\title{
A Device for Measuring the Rotational Speed of a Chain Sprocket of a Petrol Chainsaw
}

\author{
Mateusz Wróbel ${ }^{1 *}$, Bartosz Jakubek ${ }^{1}$, Wojciech Rukat ${ }^{1}$ \\ 1 Faculty of Mechanical Engineering, Institute of Applied Mechanics, Poznan University of Technology, \\ Piotrowo 3 st, 60-965 Poznań, Poland \\ * Corresponding author's email: mateusz.wrobel@put.poznan.pl
}

\begin{abstract}
The procedure for determining the frequency-weighted RMS values of vibration accelerations in the case of petrol chainsaws proposes equal time shares of three operation modes of the chainsaw. In order to assess the actual operator's vibration exposure, it is necessary to precisely determine the above-mentioned shares. In real-life conditions operation of chainsaws is characterized by frequent and significant rotational speed changes depending on the operation mode. Therefore, a prototype of dedicated device for measuring the rotational speed of a chain sprocket was developed. The article presents development requirements, encountered problems and their solutions, the prototype itself and functional test results.
\end{abstract}

Keywords: chainsaw, rotational speed measurement, chain sprocket, magnetic field, hall effect sensor.

\section{INTRODUCTION}

Chainsaws belong to the group of power tools, whose operator is exposed to vibration accelerations exceeding threshold limit values (TLV) $[1 \div 3]$. Legal regulations impose on manufacturers the obligation to inform the user about values of vibration accelerations generated by the device [4]. Measurements of these values in relation to petrol chainsaws are carried out in laboratory conditions in accordance with a strictly defined procedure. The conditions in which these tests are carried out may significantly differ from the actual conditions occurring during a typical operation of the device. Therefore, the declared vibration acceleration values should be treated as approximation. While determining the equivalent frequency-weighted RMS value of vibration accelerations $a_{h v, e q}$ generated by petrol chainsaws, three basic load states of the drive unit (chainsaw operation modes) are distinguished. These are: Idle, Full Load and Racing.

The $\mathrm{a}_{\text {hveq }}$ emitted on the handles of chainsaws are determined in accordance with ISO 7505 and ISO 22867 [5, 6]. In this standard procedure it is assumed that the percentages of the duration of the aforementioned operation modes are equal to each other and amount to $1 / 3$ of the total device operation time (TDOT). In such a case, the value of $a_{h v, e q}$ is determined according to the following relationship:

$$
a_{\mathrm{hv}, \mathrm{eq}}=\sqrt{\frac{1}{3}\left(a_{\mathrm{hv}, \mathrm{ID}}^{2}+a_{\mathrm{hv}, \mathrm{FL}}^{2}+a_{\mathrm{hv}, \mathrm{RA}}^{2}\right)}
$$

where: $a_{h v, e q}-$ equivalent vibration value,

$a_{h v, I D}-$ vibration level measured while idle speed,

$a_{h v, F L}-$ vibration level measured under full load,

$a_{h v, R A}-$ vibration level measured while racing speed.

In field (forest) conditions, the dominant operation mode in the TDOT is the idle speed mode - during which the operator moves within the working field holding the device in his hands. The share in TDOT of the full load 
mode associated with cutting wood material is comparable to the idle mode. Prolonged operation at maximum speed without load should be avoided and may damage the saw, thus its share in the TDOT is small.

The frequency-weighted RMS values of vibration accelerations determined separately for each of the chainsaw's operating modes $-a_{h v, i}$, differ from each other. This difference has been confirmed and reported in several articles [7, 8]. The use of equal time shares, according to the standard, in the TDOT may cause the declared $a_{h v, e q}$ determined in laboratory conditions to differ significantly from that which would be measured in the field conditions. The determined $a_{h v, e q}$ affects the maximum allowable operating time of the device $[9 \div 11]$.

Due to the construction of a petrol chainsaw, the operation modes of the chainsaw can be distinguished on the basis of its rotational speed. According to the data provided in the tested device manual [11], four characteristic values of rotational speed of the drive unit can be distinguished during operation. These are:

- idle speed - approx. 2800 RPM,

- reaction speed of the centrifugal clutch approx. 5100 RPM,

- full load - speed range from approx. 6000 to approx. 12000 RPM,

- maximum revolutions - approx. 13500 RPM.

Research covering observation of changes in the rotational speed of the chainsaw drive and related phenomena (including clutch slips) was carried out by A. Gendek $[13 \div 15]$. However, the measurements were carried out on a stationary test stand under conditions deviating from those prevailing in the field. Considering the differences in rotational speed accompanying operation modes of the device, as well as the desire to test the device in real-life conditions, a decision was made to develop a measurement method / measuring device that would allow us to determine the actual percentage shares in TDOT of operation modes of the chainsaw using a tachometric signal.

There are many ways to measure rotational speed [16]. In the case of contact measurements, the principal of the operation of the measuring system is the mechanical coupling between the rotating element and the measuring transducer, i.e. tachogenerators. Tachogenerators generate a continuous signal whose parameters - voltage, current and frequency (depending on the type of generator used) are proportional to the rotational speed [17].

Non-contact measurements are divided into: optical methods [18], electromagnetic methods [19:21] and strobe measurements [22], depending on the nature of the physical phenomenon that is the basis of their operation. The principal of most of these measurements, regardless of the type of transducer, is counting the number of pulses per time unit, then calculating the rotational speed. Depending on the type, optical sensors operate with the use of various types of electromagnetic wavelength range - visible range, infrared or laser light. Due to the principle of operation, electromagnetic sensors are divided into: inductive, capacitive and Hall sensors. Meanwhile the stroboscopic measurement is based on the synchronization of the lamp operating frequency with the rotational frequency of the element using the optical phenomenon, i.e. the stroboscopic effect.

The rotational speed can also be measured indirectly. Wu, Ding and Han [23] presented a method using accelerometer measuring centrifugal force which is proportional to the rotational speed squared.

\section{AIM OF THE RESEARCH AND DESIGN ASSUMPTIONS}

The motivation for the design and construction of the device was the need to record rotational speed of the chain sprocket during the 8-hour working day of the operator. The data recorded in this way will serve as the basis for determining the real time shares of operation modes of the chainsaw in the TDOT. Typical operating conditions of a petrol chainsaw (forest) determine majority of the requirements for both the construction of the device and the software intended for recording the rotational speed of the chain sprocket:

- the device should have small size so that the operator of the chainsaw could carry the device with him; the presence of the device neither should cause discomfort to the operator nor pose a threat to his health or life while operating the chainsaw,

- the selected type of sensor has to withstand the environmental conditions around the chainsaw; the selection of the sensor have to consider the presence of dust, wood chips and grease,

- the battery supply of the measuring device is necessary due to the inaccessibility to the mains,

- sending the recorded data directly to the computer via wire transmission would limit the mobility of the chainsaw, hence it has to be excluded, 
- the fact that there is often no access to the Internet or GSM network at the chainsaw operation workplace has to be taken into account,

- registration of the rotational speed of the chain sprocket has to cover the range from 2800 up to 13500 RPM,

- all delays related to the transmission of data, buffering of the transmitted data, as well as their processing and saving should be minimized, due to the frequency of pulse recording,

- determination of the instantaneous rotational speed of the chain sprocket should have the highest possible accuracy.

\section{DEVICE DESIGN AND METHODOLOGY OF ROTATIONAL SPEED MEASUREMENT}

To measure the rotational speed of the chain sprocket, the use of one of three types of sensors was considered: an optical sensor, an inductive sensor and a Hall effect sensor.

Proximity optical sensors are often used to detect the presence of objects made of non-transparent materials. They are characterized by a high switching frequency and small dimensions. The disadvantage of these sensors is troublesome work in dusty and dirty environment due to very sensitive optical systems $[16 \div 18]$. Because of that, the use of a proximity optical sensor for measurements during wood processing is not recommended.

Inductive sensors are used to detect metal objects. Due to the possibility of working in a heavily polluted environment, they are often used in industry. The disadvantage of inductive sensors is undoubtedly the small working zone which range from a few to several dozen millimeters, depending on the size of the sensor $[19,20]$. The size of the detected element is also important. The detection of objects smaller than the sensor face may be the problem.

An inductive sensor was initially selected and mounted at the end of the chainsaw's guide in such a way that it was possible to detect the presence of the cutting blade moving within the sensor working zone. The results obtained with the manual feed of the chain turned out to be initially promising. However, during the following tests, it was observed that the sensor, under the influence of vibrations emitted during the chainsaw operation, did not detect most of passages of the cutting blades within its working zone.

Eddy current sensors can be used to detect the presence of an electromagnetic field. However, the most common supply voltage of this type of sensors is between 6 and $36 \mathrm{~V}$. Supplying the eddy current sensor with a lower voltage may cause its incorrect operation [21]. Therefore it has been ruled out due to the considered battery supply of the measuring device (maximum supply voltage of $5 \mathrm{~V}$ ).

Hall sensors are most often used as proximity sensors for objects made of magnetic materials. They also allow one to measure magnetic $\mathrm{H}$-field or electric current. Hall sensors in comparison to inductive sensors are insensitive to small changes of the distance between the detected object and the sensor face [22, 23]. Due to its stable operation in a polluted environment this type of sensor was selected for construction of the prototype of the measuring device for the rotational speed of the chain sprocket. Consequently, it was necessary to mount a small neodymium magnet on the chain sprocket. The magnet was mounted in such a way that one turn of the chain sprocket caused one pulse to be registered by the measuring device. Views of magnets mounted on chain sprockets are presented in the following pictures. a)

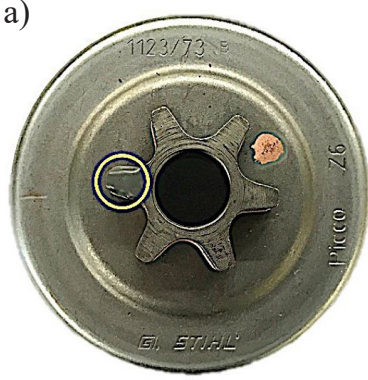

b)

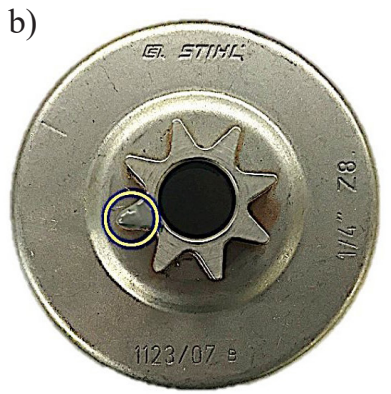

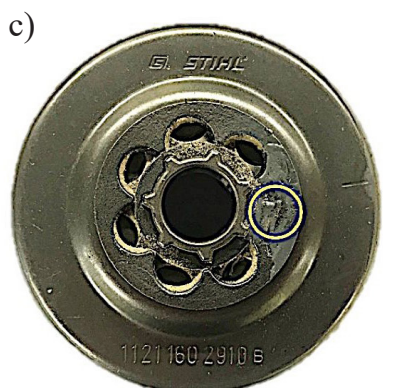

Fig. 1. Views of three different types of chain sprockets with marked places where the magnets were mounted a) monolithic wheel with 6 teeth, b) monolithic wheel with 8 teeth, c) ring wheel 
Table 1. Technical parameters of Hall effect sensor AH49E [24]

\begin{tabular}{|l|c|}
\hline Supply voltage & from $2.3 \mathrm{~V}$ to $8 \mathrm{~V}$ \\
\hline Sensitivity & $1.6 \mathrm{mV} / \mathrm{GS}$ \\
\hline Supply current & $3.5 \mathrm{~mA}$ (for $5 \mathrm{~V}$ ) \\
\hline Dimensions & $3 \times 4 \times 1.6 \mathrm{~mm}$ \\
\hline
\end{tabular}

In the prototype of the device Hall effect sensor AH49E was used. The technical parameters of the sensor are presented in Table 1.

The device was designed based on the STMicroelectronics STM32F103RBT6 microcontroller [25]. The following properties ruled in favor for the use of this microcontroller:

- the maximum clock frequency of $72 \mathrm{MHz}$ allows one to record and save to the external memory data related to the rotation of the chain sprocket continuously and without generating excessive delays,

- the microcontroller has a sufficient number of GPIO ports (inputs / outputs), built-in 16-bit timers and communication interfaces enabling the design and execution of any systems for recording, registration or data transfer,

- thanks to the low supply voltage $(3.3 \mathrm{~V})$ and low power consumption in standard and low power operating modes, STM32 microcontrollers from the F1 family can be successfully used in battery-powered systems,

- large availability on the market of microcontrollers in the form of a chip and evaluation boards facilitating prototyping.

The STM32 NUCLEO-F103RB evaluation board containing the above-mentioned STM32F103RBT6 microcontroller was used in the development of the prototype of measuring device.
The AH49E sensor provides an ana$\log$ output signal. It was decided to design an additional comparator system with the possibility of adjusting the activation threshold based on the LM393 system, which allowed us to convert analog AH49E output signal to digital signal in the range of $0-3.3 \mathrm{~V}$. The output signal from the comparator was led to one of the GPIO pins of the STM32 microcontroller for which external interrupt controller was activated. Such a solution accelerated the microcontroller's response to the impulse coming from the detection of the magnet in the sensor's working zone. The sensor was mounted in the chain sprocket cover (Fig. 2a). The mounting method allows one to adjust the distance between the sensor and the sprocket.

The evaluation board was powered directly from a $5 \mathrm{~V} \mathrm{DC}$ battery source. The microcontroller is not adapted to work with this voltage, therefore the board is equipped with a linear stabilizer system that converts the $5 \mathrm{~V}$ input voltage to $3.3 \mathrm{~V}$ that is safe for the microcontroller.

At the design stage, several methods of data transmission or storage were considered. The device is intended to work in field conditions where access to the 230 VAC power supply is limited or impossible. Because of that, the transmission of recorded data by a wire (e.g. serial bus or USB) or wireless (Bluetooth) directly to a PC would be difficult to implement. The need to operate an additional device and to move the workstation between subsequent tree felling and processing stations would certainly be a burden to the operator. These tasks could be delegated to additional staff. However, the presence of third parties in the vicinity of the chainsaw operation is highly undesired due to threat to health or life.

No reception of both the mobile network and the Internet often occurs in places where trees are
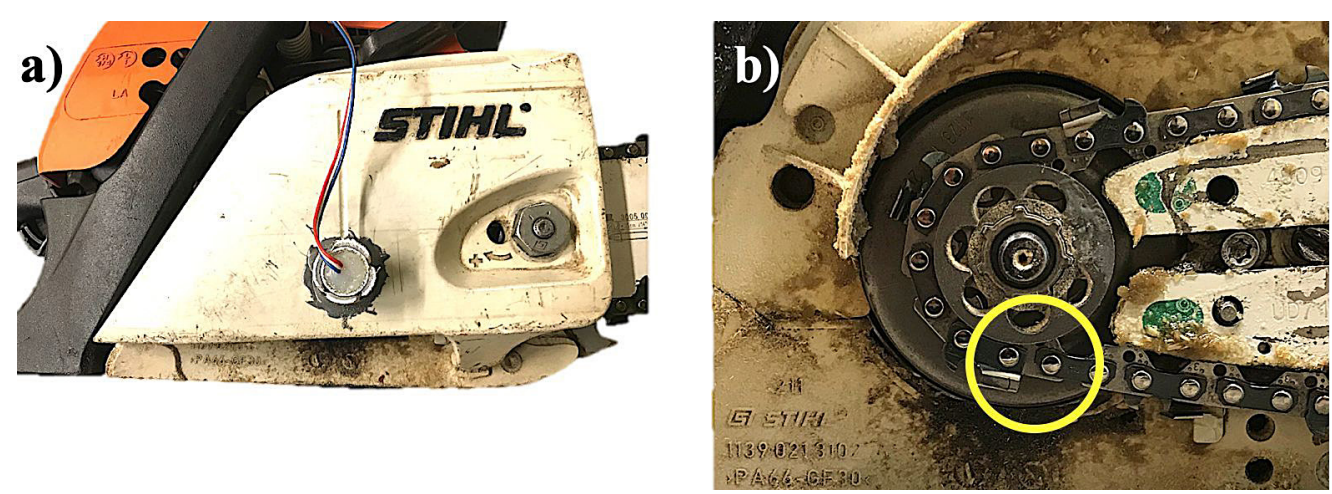

Fig. 2. View of: a) the chain sprocket cover with the Hall sensor mounted, b) the chain drive system with the sensor location marked 
felled. Therefore, it is possible that attaching a GSM or WIFI module to the device would not guarantee successful data transmission. It was decided that the optimal solution to record the rotational speed of the chain sprocket performed away from the electrical and communication networks would be to directly save the data on a microSD card. The communication of the microcontroller with the microSD card takes place via SPI (Serial Peripheral Interface), which enables data transmission at a speed of 18 Mbit/s. The software implementation of the FatFs library allows one to create, edit and save files on the card in the .txt format, which can then be analyzed on any workstation [26]. The microSD card is also characterized by low power consumption, unlike the most commonly used Bluetooth, GSM or WIFI modules. This may significantly extend the maximum time of the device's operation in the field.

The software implemented on the microcontroller was developed in the STM32CubeIDE application. The program code was implemented in such a way to obtain the registration and recording of the rotational speed of the sprocket without any delay. A simplified block diagram of the measurement path is shown in Figure 3.

A view of the prototype of the measuring device is shown in Figure 4.

The principle of operation of the device is as follows. The start-up takes place immediately after connecting the device to the power supply $(5 \mathrm{~V})$. The microSD card is also initialized during the start-up. In case the card is not successfully initialized, the program will not proceed to the execution of further instructions. The recording is started after changing the position of a switch. At the same time, a timer starts counting the time with an accuracy of $0.1 \mathrm{~ms}$ and a file in the .txt format with an individual name for each measurement is created in the microSD card memory. After the appearance of a low state on the input pin of the microcontroller, the interrupt function is started. The body of the

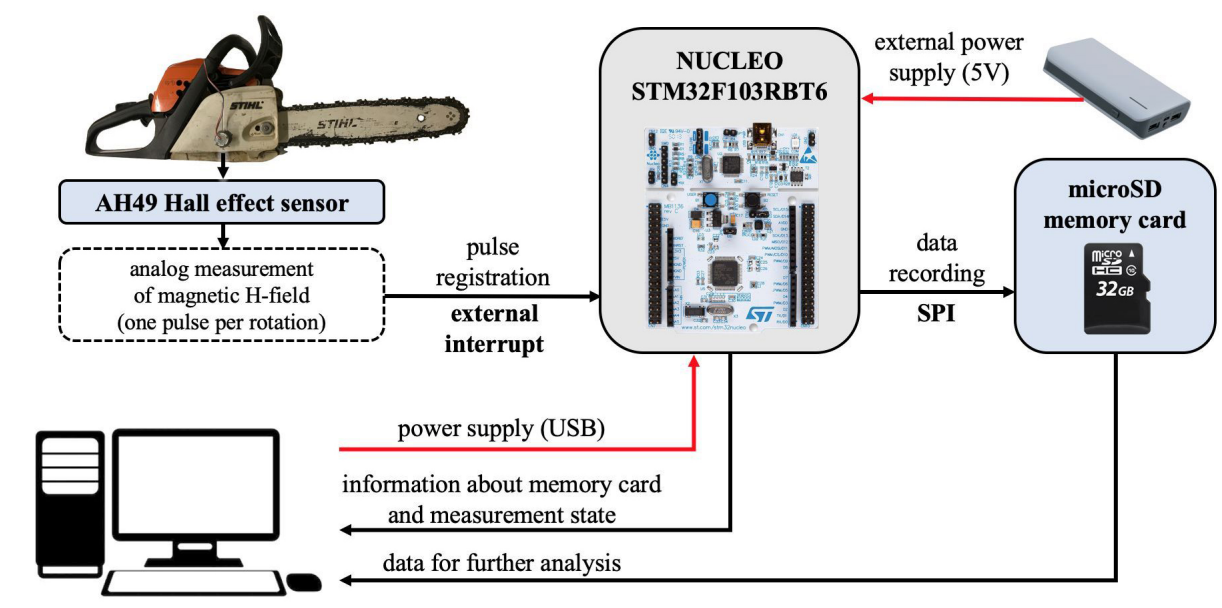

Fig. 3. Block diagram of the measuring path for recording the rotational speed of the chain sprocket

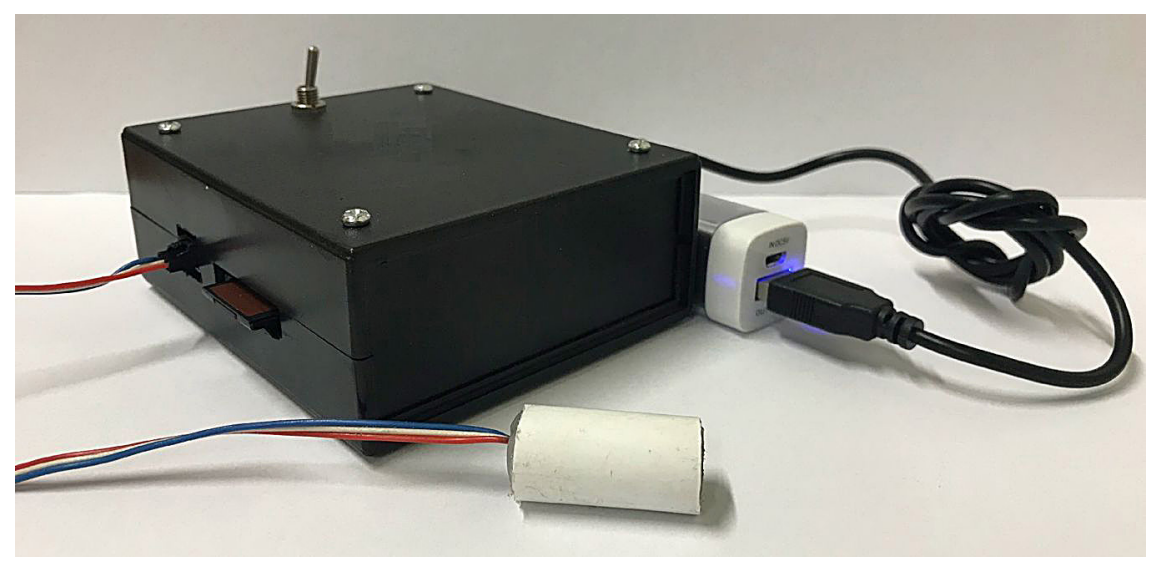

Fig. 4. A view of the prototype of measuring device for recording the rotational speed of the chain sprocket of the petrol chainsaw 
function consists of instructions for finding the end of the file and writing the instantaneous speed value there. The instantaneous rotational speed is calculated from the formula:

$$
\mathrm{rpm}_{\text {inst }}=60 \cdot \frac{1}{\Delta t}=\frac{60 \cdot 10^{5}}{t_{(i+1)}-t_{i}}\left[\frac{1}{\min }\right]
$$

where: $\Delta t$ - time difference between two consecutively appearing pulses $\left[\mathrm{s} \cdot 10^{-4}\right], t_{i}$ - time of appearance of the $\mathrm{i}$-th pulse $\left[\mathrm{s} \cdot 10^{-4}\right]$, $t_{i+1}$ - time of appearance of the following pulse $\left[\mathrm{s} \cdot 10^{-4}\right]$.

Moreover, it is possible to connect the device directly to the USB port of a PC and to monitor the operating status of the device and the status of the memory card.

\section{TESTS RESULTS}

The correctness of operation of the presented measuring device in terms of the measurement of the rotational speed of the chain sprocket has been verified. In this chapter the functional test results are presented. Figure 5 shows changes of the instantaneous chain sprocket rotational speed during cutting a $210 \times 190 \mathrm{~mm}$ testing beam (the beam was assembled from $670 \times 95 \mathrm{~mm}$ pine beams). The graph is supplemented by pictures of the following phases of operation.

In the graph, at the end of the 1 st test second, the chainsaw clutch starts to transfer the torque. Then the chainsaw accelerates to the maximum speed. The recording of the highest value of the rotational speed took place in the 2nd second of the test. The maximal rotational speed was equal to $13043.5 \mathrm{rpm}$ (which corresponds to a single rotational time of $4.6 \mathrm{~ms}$ ). The longer is the cutting line the greater is the load of the chainsaw, which is accompanied by a decrease in rotational speed. One can state that as long as the cut material is free from local defects, in the form of knots or foreign bodies, there are only slight fluctuations in the instantaneous rotational speed of the chain sprocket. In the 8th second of the test, the chainsaw was stopped due to the exceeding of the maximal load torque of the engine as a result of encountering a local defect in the form of a knot in the cutting plane. The random arrangement of the beams also affected the increase in cutting resistance. Therefore, during the test, the chainsaw worked in a wide range of rotational speeds from 5000 to approx. $10000 \mathrm{rpm}$. After the full cross-cut of the beam was made, the rotational speed dropped to zero. The test confirmed that the

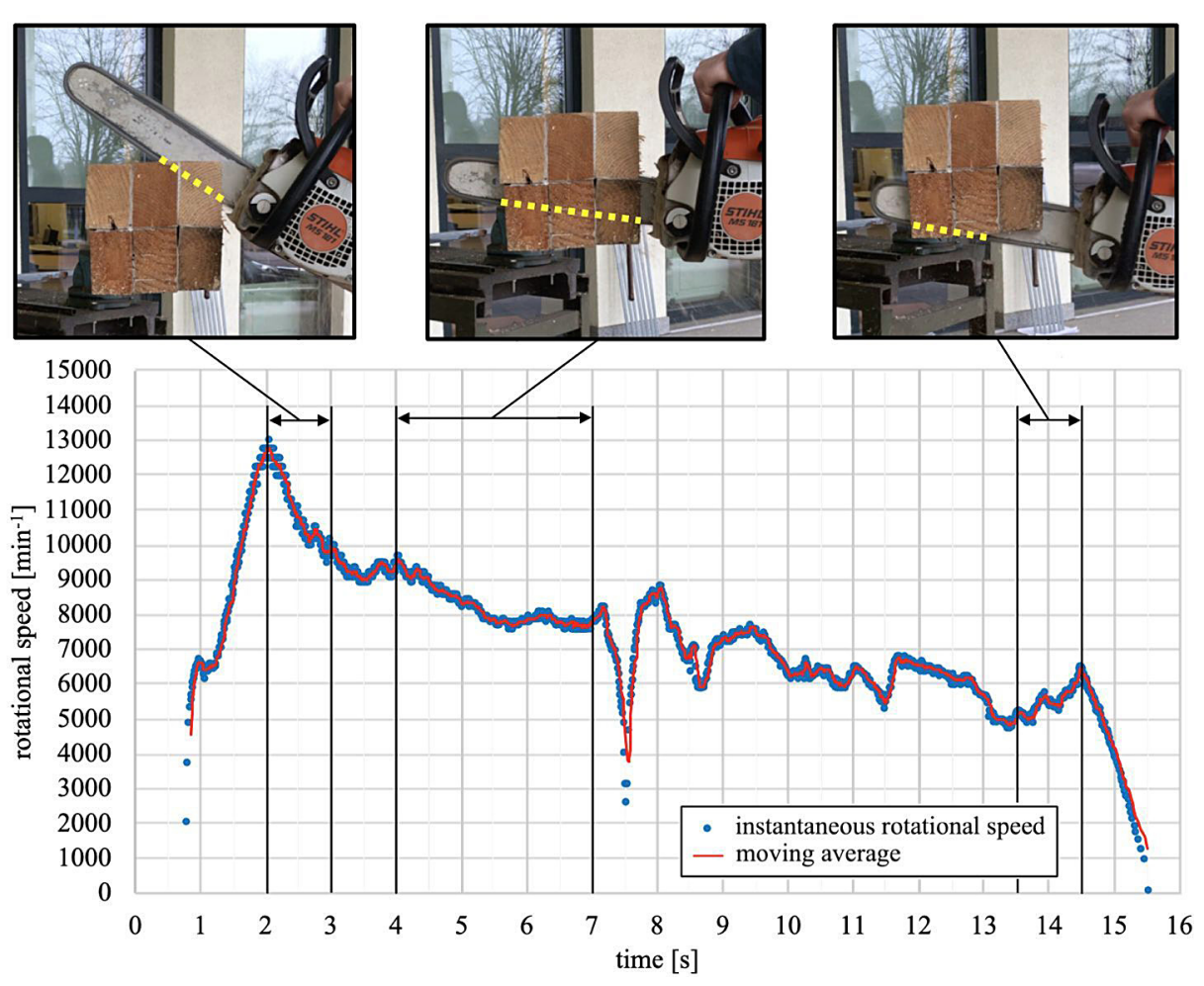

Fig. 5. Instantaneous values of rotational speed of the chain sprocket registered during the test simulating log bucking; the chart and phases of the cutting process 


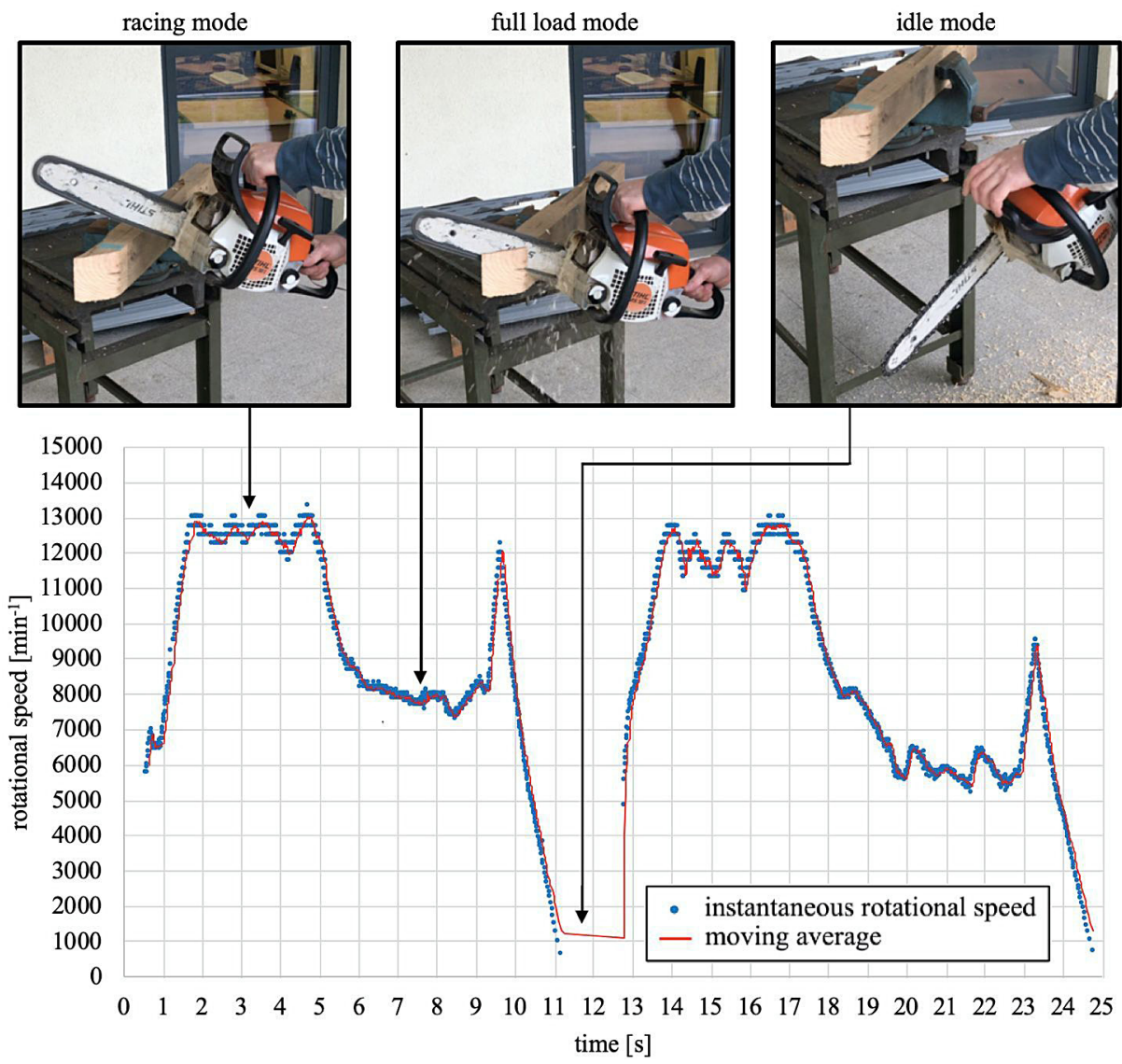

Fig. 6. Instantaneous values of rotational speed of the chain sprocket registered during the test covering three operation modes of the petrol chainsaw; the chart and pictures of chainsaw in these operation modes

presented measuring device is capable to measure the rotational speed of the chain sprocket with an accuracy that allows us to identify the operation mode of the chainsaw.

The graphic representations of measured rotational speed in this article have been presented with the greatest possible resolution (the number of points in the graphs corresponds to the actual number of rotations made by the chain sprocket).

Another test involved two cross-cuts of a beam with a cross-section area of approx. $100 \mathrm{~cm}^{2}$. In this test, the operating time of the chainsaw in racing mode was intentionally extended, which should be avoided. Figure 6 shows changes of the instantaneous chain sprocket rotational speed during cutting a $110 \times 90 \mathrm{~mm}$ pine beam. The graph is supplemented by pictures of the operation modes of the chainsaw.

This test allowed us to conclude that the racing mode of operation occurs when the saw operates in the range above $10000 \mathrm{rpm}$. The full load mode covers the speed range from 5000 up to $10000 \mathrm{rpm}$. Idling occurs when the chain sprocket does not move. Unfortunately, the adapted method of rotation speed estimation for identification of chainsaw's operation modes has some limitations. Data limited only to rotation speed does not allow us to recognize transients, i.e. acceleration and braking. Rotation speeds in these states are contained in the full load mode rotation speed range. Moreover, there is no difference in such recorded data between idle mode and turned off chainsaw. In order to distinguish idle mode from turned off device additional channel should be implemented. This channel should carry information on engine status.

\section{CONCLUSIONS}

The proposed solution meets all design assumptions. The error of estimation of the instantaneous rotational speed depends on the rotational speed itself and ranges from $40 \mathrm{rpm}$ (5100 rpm - clutch engagement) to $300 \mathrm{rpm}$ (maximum declared engine rotational speed). This accuracy may seem low, but it is sufficient for either identifying chainsaw's operation mode or determining the various phases of 
the chainsaw's operation. More accurate results can be obtained by averaging the input data.

The selected hall sensor turned out to be adequate. The chainsaw's operating conditions, the presence of grease and wood chips, do not affect the sensor's operation. No interference and errors were found in the registered data.

The battery power supply guarantees the possibility of long-term work in the field. The working time is defined by the capacity of the battery used. Due to its low weight and dimensions, the device can be carried by the operator or can be mounted directly to the chainsaw.

The operation of petrol chainsaws is characterized by frequent and significant changes in the instantaneous rotational speed. The selected method of data recording turned out to be effective, but the analysis has to be performed on the workstation. The measuring device does not hinder the work of the chainsaw operator and does require neither presence of third parties in the measuring arena nor special training for the operator. However, identification of all chainsaw's operation modes requires further work.

\section{Acknowledgements}

The work presented results of the research that was funded with grant $0612 / \mathrm{SBAD} / 3567 / 2021$ for education allocated by the Ministry of Science and Higher Education of the Republic of Poland.

\section{REFERENCES}

1. Kováč J., Krilek J., Dado M., Beňo P. Investigating the Influence of Design Factors on Noise and Vibrations in the case of Chainsaws for Forestry Work. FME Transactions. 2018;46(4):513-519.

2. Matache M.G., Munteanu M., Dumitru D. M., Epure M. Evaluation of hand transmitted chainsaw vibrations during wood cutting. E3S Web of Conferences. 2020;180(03013):1-7.

3. Landekić M., Bačić M., Pandur Z., Šušnjar M. Vibration Levels of Used Chainsaws. Forests. 2020;11(249):1-10.

4. DYREKTYWA 2006/42/WE PARLAMENTU EUROPEJSKIEGO I RADY z dnia 17 maja 2006 r. w sprawie maszyn, zmieniająca dyrektywę 95/16/WE

5. ISO 7505:1986 Forestry machinery - Chain saw Measurement of hand-transmitted vibration.

6. ISO 22867:2011 Forestry and gardening machinery - Vibration test code for portable handheld machines with internal combustion engine - Vibration at the handle.
7. Rukat W., Jakubek B. The influence of the cutting tooth design and wear of a saw chain on the vibration level of a chainsaw. Vibrations in Physical Systems. 2017;28(2017009):1-8.

8. Wójcik K. Analysis of processing operation time and it's percent share in timber harvesting with the chain saws. Agricultural Engineering. 2007;50:71-77.

9. Neri F., Laschi A., Foderi C., Fabiano F., Bertuzzi L., Marchi E. Determining Noise and Vibration Exposure in Conifer Cross-Cutting Operations by Using LiIon Batteries and Electric Chainsaws. Forests. 2018;9(501):1-13.

10. Rukat W., Barczewski R., Jakubek B., Wróbel M. The comparison of vibro-acoustic impact of chainsaw with electric and combustion drives. MATEC Web of Conferences. 2018;182(02020):1-7.

11. Rukat W., Jakubek B., Barczewski R., Wróbel M. The influence of the direction of wood cutting on the vibration and noise of chainsaws. Tehnički vjesnik. 2020;27(6):1879-1886.

12. Service and repair manual for the Stihl MS 181 saw - version 2015.

13. Gendek A. Research of clutch temperature increase of chain saw (in Polish). Technika Rolnicza Ogrodnicza Leśna. 2011;5:5-7.

14. Gendek A. The method of measuring the rotational speed of the chainsaw elements (in Polish). Przegląd Techniki Rolniczej i Leśnej. 1999;8:20-23.

15. Gendek A., Kociołek M. Stand for measuring rotational speeds and slips in the coupling of a chainsaw (in Polish). Technika Rolnicza Ogrodnicza Leśna. 2006;8:23-25.

16. Zheng Z., Zhang R.J. Classification Research of Rotation Speed Measurement. Applied Mechanics and Materials. 2014;457-458:998-1003.

17. Safiullin R. A., Yangirov I.F. Tachogenerator for processing Signals and Data from Electrical Machine. 2020 International Youth Conference on Radio Electronics, Electrical and Power Engineering (REEPE), Moscow, Russia 2020, 1-5,

18. Ma Z.Q., Zhang R., Kang D.L., Yang W. A Research of High Precision Rotational Speed Measurement System Based on Infrared Sensor and Microcontroller. Applied Mechanics and Materials. 2013;278-280:680-683.

19. Kędzierski Ł. High speed imaging method for rotational speed calibration. Przegląd elektrotechniczny (in Polish). 2019;5:184-187.

20. Li L., Hu H., Qin Y., Tang K. Digital Approach to Rotational Speed Measurement Using an Electrostatic Sensor. Sensors (Basel). 2019;19(11):2540.

21. Wang L., Yan Y., Hu Y., Qian X. Rotational Speed Measurement Using Single and Dual Electrostatic Sensors. IEEE Sensors Journal. 2015;15(3): 1784-1793. 
22. Jurevic M., Krsulja M., Katalinic B., Car Z., Sikulec L., Automatic Measurement of Rotational Speeds and Lathe Maintenance. Annals of DAAAM for 2012 \& Proceedings of the 23rd International DAAAM Symposium. 2012;23(1):775-778.

23. Wu C., Ding H., Han L. Design of a Centrifugal Force-Based Speed Sensor for Downhole Turbodrills. Journal of Sensors. 2018:1-12.

24. Hsiao K., Nangeroni P., Huber M., Saxena A., Ng A.Y. Reactive Grasping Using Optical Proximity Sensors. IEEE International Conference on Robotics and Automation. Kobe, Japan 2009, 2098-2105.

25. Kazanskiy N.L., Khonina S.N., Butt M.A., Kaźmierczak A., Piramidowicz R. State-of-the-Art Optical Devices for Biomedical Sensing Applications - A Review. Electronics. 2021;10(8):973.

26. Karbowniczek M. Zbliżeniowe czujniki optyczne w praktyce inżynierskiej (in Polish). Elektronika Praktyczna. 2015; 4:135-139.

27. KAMAN Measuring and Memory Systems. Inductive Technology Handbook; 2008.
28. Zhao Y., Fang Y., Yang J., Zhang W., Ge X., Cao S., Xia X. An Implementation Method for an Inductive Proximity Sensor with an Attenuation Coefficient of 1. Energies. 2020;13:6482.

29. Ripka P., Blažek J., Mirzaei M., Lipovský P., Šmelko M., Draganová K. Inductive Position and Speed Sensors. Sensors. 2020;20:65.

30. Lozanova S., Ivanov A., Roumenin C. A Novel Three-Axis Hall Magnetic Sensor. Procedia Engineering. 2011;25:539-542.

31. Popovic R.S., Boero G., Besse P.A. Micro-Hall Magnetic Sensors: Physics, Technologies and Applications. In: Yurish S.Y., Gomes M.T.S.R. (eds) Smart Sensors and MEMS. NATO Science Series. 2004; 181:229-253.

32. Diodes Incorporated. Linear Hall-effect IC AH49E. BCD Semiconductor Manufacturing Limited; 2009.

33. STMicroelectronics. STM32F103x8, STM32F103xB datasheet; 2015

34. Paprocki K. Mikrokontrolery STM32 w praktyce (in Polish). BTC; 2009. 